Revista Brasileira de Agricultura Irrigada v.10, nº.4, p. 767 - 776, 2016

ISSN 1982-7679 (On-line)

Fortaleza, CE, INOVAGRI - http://www.inovagri.org.br

DOI: $10.7127 /$ rbai.v10n400409

Protocolo 409.16 - 28/06/2016 Aprovado em 03/08/2016

\title{
DEMANDA HÍDRICA DO CAFEEIRO CONILON IRRIGADO POR DIFERENTES SISTEMAS DE IRRIGAÇÃO
}

\author{
Luan Peroni Venancio ${ }^{1}$, Fernando França Cunha ${ }^{2}$, Everardo Chartuni Mantovani ${ }^{3}$
}

\begin{abstract}
RESUMO
O estado do Espírito Santo é o maior produtor mundial de café Conilon, sendo cultivado quase que exclusivamente sob irrigação. O conhecimento da demanda hídrica é fundamental para otimização do uso da água, energia e dos insumos. O objetivo do presente trabalho foi simular a demanda hídrica do cafeeiro Conilon irrigado pelos sistemas de gotejamento, microjet e aspersão, utilizando dados climáticos históricos da região, provenientes da estação meteorológica automática do INMET, em Linhares-ES. Nas simulações utilizou-se o software IRRIPLUS ${ }^{\circledR}$. Utilizaram-se os dados horários que posteriormente foram convertidos a dados diários de janeiro de 2007 a dezembro de 2013, totalizando sete anos. Coletaram-se também informações representativas da cultura, do solo, da água e dos sistemas de irrigação, para realização da simulação. Observou-se uma evapotranspiração (ETc) média de 27,8 e 26,0\% maior no sistema por aspersão convencional do tipo setorial em comparação aquelas irrigada por gotejamento e microjet, respectivamente. A lâmina bruta aplicada nas irrigações é em média 5,8 e 8,7\% maior no sistema por aspersão setorial em comparação aos sistemas por gotejamento e microjet, respectivamente, pois estes últimos, apesar de menor ETc são manejados com intervalo entre irrigações menores, implicando o melhor aproveitamento da precipitação pluvial no cafeeiro irrigado por aspersão setorial. A tecnologia e os dados gerados são fontes de informação para auxiliar técnicos e engenheiros na escolha do melhor sistema de irrigação e do volume de água requerido por cada um deles.
\end{abstract}

Palavras-chaves: cafeicultura, simulação, agricultura irrigada.

\section{HYDRIC DEMAND OF CONILON COFFEE IRRIGATED BY DIFFERENT IRRIGATION SYSTEMS}

\footnotetext{
${ }^{1}$ Doutorando, Departamento de Engenharia Agrícola e Ambiental, Universidade Federal de Viçosa, Viçosa, Brasil, CEP: 36570-900, e-mail: lpagronomo1990@gmail.com

${ }^{2}$ Prof. Adjunto, Departamento de Engenharia Agrícola e Ambiental, Universidade Federal de Viçosa, Viçosa, Brasil, CEP: 36570-900, e-mail: fernando.cunha@ufv.br

3Prof. Titular Aposentado, Departamento de Engenharia Agrícola e Ambiental, Universidade Federal de Viçosa, Viçosa, Brasil, CEP: 36570-900, e-mail: everardo@ufv.br
} 


\begin{abstract}
The Espírito Santo state is the greatest world's producer of Conilon coffee and this is cultivated almost exclusively under irrigation. Knowing the hydric demand is fundamental for water, energy and inputs use optimization. The objective this work was to simulate the hydric demand of irrigated Conilon coffee by drip systems, microjet and sprinkler, utilizing climate historical data of the regions, obtained from the INMET automatic meteorological station in LinharesES. In the simulations was used IRRIPLUS software. Hourly data were taken and posteriorly were converted to daily data, from January 2007 to December 2013, totalizing seven years of data. Crop, soil, water and irrigation systems representative information was also collected for the simulations. The average ETc was $27,8 \%$ and $26,0 \%$ higher in the sectorial conventional sprinkler system in comparison with those irrigated by drip and microjet, respectively. The gross irrigation depth applied in the irrigations was 5,8\% and 8,7\% bigger in the sectorial conventional sprinkler system in comparison with drip and microjet systems, respectively. The better rainwater utilization occurs to in the sectoral sprinkler irrigation system. The technology and data generated are data sources to assist technicians and engineers choosing the best irrigation systems and their required volume of water.
\end{abstract}

Keywords: coffee growing, simulation, irrigated agriculture.

\section{INTRODUÇÃO}

A cafeicultura brasileira tem sofrido mudanças significativas, principalmente em seu sistema de produção. Dentre essas mudanças, pode-se destacar a utilização da irrigação, que pode proporcionar menos riscos, mais eficiência na utilização e aplicação de insumos, além de maior produtividade e melhor qualidade do produto (OLIVEIRA et al., 2010). A utilização da irrigação na cafeicultura redesenhou a distribuição geográfica do cultivo de café no Brasil, incorporando áreas antes não recomendas para o plantio, transformando-as em novos polos de desenvolvimento da cultura e de regiões (VICENTE et al., 2015).

Existem vários sistemas de irrigação utilizados com sucesso pelos produtores de café Conilon no estado do Espírito Santo, sendo os mais utilizados a aspersão convencional, aspersão setorial, pivô central, microjet, microaspersão e gotejamento. A escolha vai depender de vários fatores, como a topografia, o espaçamento, a cultivar, a quantidade e qualidade da água disponível, a velocidade e a direção dos ventos, as condições edafoclimáticas, os níveis tecnológicos e econômicos e o custo do equipamento (FERRÃO et al., 2007).

A irrigação é responsável por grande parte do consumo de energia no meio rural.
Normalmente, o produtor rural não adota um método de controle de irrigação, usualmente irriga em excesso, tendo como consequência o desperdício de energia elétrica e de água (TURCO et al., 2012), fato comum na região de Linhares- ES.

Estima-se que a área irrigada de cafeeiro Conilon irrigada no Espírito Santo seja de 150 mil hectares, sendo a grande maioria na região norte capixaba (TEIXEIRA et al., 2012). Segundo dados da Conab (2016), esse Estado possui área de 286.371 hectares plantada com cafeeiro, sendo assim, 52,4\% da cafeicultura no ES é irrigada. Neste contexto, caracterizar os sistemas mais utilizados, irá ajudar os técnicos da região a projetar novos sistemas, dimensionar estrutura para reservar água para tal fim, e com isso fortalecer a atividade.

Os sistemas de irrigação necessitam de diferentes volumes de água para irrigar a mesma área e cultura. Essa diferença é devido a fatores primários como eficiência e fração da área molhada; e secundários como frequência da irrigação que irá proporcionar diferenças na precipitação efetiva e coeficientes de umidade do solo (Ks) (BERNARDO, 2011). No momento da seleção de um sistema de irrigação para determinada área e cultura, o volume de água e energia elétrica que serão gastos devem ser considerados. Entretanto, para o conhecimento dessas informações, ao invés de 
montar ensaios experimentais, que demandam de recursos financeiros e tempo, simulações podem ser utilizadas.

Para realização de simulações, os softwares aparecem como uma ótima ferramenta, visto que oferecem facilidade nos cálculos a partir da entrada de dados, além de evitar experimentos dispendiosos no campo. Para a agricultura irrigada, há diversos softwares que permitem realização de simulações, dentre eles, dentre eles o software IRRIPLUS ${ }^{\circledR}$, que pode ser adquirido gratuitamente no site: http://www.irriplus.com.br/software-irriplus (IRRIPLUS TECNOLOGIA).

Neste contexto, o objetivo do presente trabalho foi simular a demanda hídrica do cafeeiro Conilon irrigado pelos sistemas de gotejamento, microjet e aspersão, utilizando dados climáticos históricos da região, provenientes da estação meteorológica automática do INMET em Linhares-ES.

\section{MATERIAL E MÉTODOS}

O estudo foi realizado por meio de simulações efetuadas para as condições de Linhares-ES, utilizando o software IRRIPLUS ${ }^{\circledR}$, desenvolvido no departamento de Engenharia Agrícola da Universidade Federal de Viçosa (DEA/UFV). Os dados meteorológicos utilizados no trabalho são provenientes da estação meteorológica automática do Instituto Nacional de Meteorologia (INMET) em Linhares-ES, que fica localizada na latitude $19^{\circ}$ 21' 24" S, longitude $40^{\circ} 4^{\prime}$ '”' $\mathrm{W}$ e altitude de 38 metros. O código da estação atribuído pelo (INMET) e pela Organização Mundial de Meteorologia (OMM) é A614 e 86805, respectivamente.

Os dados fornecidos pelas estações automáticas do INMET são dados horários, como no presente estudo trabalhou-se com dados diários, realizou-se a transformação dos mesmos. Utilizou-se sete anos de dados, de janeiro de 2007 a dezembro de 2013.

Considerou-se na simulação um plantio realizado em primeiro de janeiro de 2007, com o cafeeiro passando por quatro fases fenológicos até chegar a fase adulta, denominadas de fase de plantio, crescimento vegetativo 1 , crescimento vegetativo 2 e adulta, com duração de 365 dias cada. O quinto, sexto e sétimo ano, foram definidos como fase adulta, portanto, as características da cultura para estes anos, foram idênticas ao quarto. Coletaram-se também informações representativas da cultura, do solo, da água e dos sistemas de irrigação, com profissionais e empresas da região e na literatura.

De acordo com Viana et al. (2011) no município de Linhares, são encontrados nas planícies costeiras os solos do tipo arenoquartzosos profundos, aluviais eutróficos e distróficos na área de influência do Rio Doce, com predominância para o primeiro, hidromórficos e podzol. Já nas planícies de tabuleiros predomina o solo do tipo Latossolo Vermelho Amarelo coeso distrófico e na região serrana do tipo Latossolo vermelho amarelo.

No presente estudo, utilizou-se o Latossolo Vermelho Amarelo como o tipo de solo representativo da região cafeeira, e suas características físico-hídricas adotadas na simulação foram as seguintes: umidade na capacidade de campo de $0,34 \mathrm{~kg} \mathrm{~kg}^{-1}$, umidade no ponto de murcha de $20 \mathrm{~kg} \mathrm{~kg}^{-1}$, densidade do solo de $1,20 \mathrm{~g} \mathrm{~cm}^{-3}$ e taxa de infiltração estável de $40 \mathrm{~mm} \mathrm{~h}^{-1}$. Considerou-se tais valores representativos de uma camada de 0 a $40 \mathrm{~cm}$ de profundidade.

Em relação as características da cultura do cafeeiro Conilon, as seguintes informações foram levantadas e utilizadas na simulação: espaçamento de 1,0 metro entre plantas e 3,30 metros entre linhas; profundidade efetiva do sistema radicular (Z) de 15, 25, 40 e $50 \mathrm{~cm}$; porcentagem de área sombreada (PAS) de 15, 25, 40 e 60\%; valores médios de coeficiente de cultura (Kc) de 0,5; 07; 0,9 e 1,0, baseado no trabalho de Santinato (1996). Os valores acimas citados para o Z, PAS e Kc correspondem as fases de plantio, crescimento vegetativo 1 , crescimento vegetativo 2 e adulta, respectivamente. $\mathrm{O}$ fator de segurança de água no solo (f) considerado foi de $50 \%$.

No que diz a respeito aos sistemas de irrigação da região, destacam-se como mais utilizados para o cafeeiro a aspersão convencional do tipo setorial, a irrigação 
localizada por gotejamento e por microjet. Os sistemas de aspersão setorial, vieram em substituição a aspersão convencional e tem como característica principal a baixa vazão dos aspersores, geralmente inferiores a $2 \mathrm{~m}^{3} \mathrm{~h}^{-1}$.

As características do sistema de irrigação por aspersão setorial utilizada na simulação foram: vazão de $1,05 \mathrm{~m}^{3} \mathrm{~h}^{-1}$; pressão de serviço (PS) de 25 m.c.a; espaçamento de 12 metros entre aspersores e 15 metros entre linhas laterais; porcentagem de área molhada (PAM) de 100\%; e eficiência de irrigação (Ei) de 79\%. Foi considerado como momento ideal para o retorno da irrigação, a igualdade da umidade do solo a umidade no fator de segurança (f).

Para a irrigação localizada por gotejamento, utilizou-se: vazão do gotejador de 2,3 $\mathrm{L} \mathrm{h}^{-1}$; PS de 10 m.c.a; espaçamento de 0,5 metros entre gotejadores e 3,3 metros entre linhas laterais (uma linha por fileira de planta); PAM de 30\%; Ei de $90 \%$ e turno de rega fixado em 2 dias.

O microjet reuni o baixo custo de um gotejador com a distribuição de água do microaspersor, resultando em uma opção econômica. Para a irrigação localizada por microjet, utilizou-se: vazão do microaspersor de $13 \mathrm{~L} \mathrm{~h}^{-1}$; PS de 15 m.c.a; espaçamento de 1,0 metros entre os emissores e 3,3 metros entre linhas laterais (uma linha por fileira de planta); PAM de 35\%; Ei de 90\% e turno de rega fixado em 2 dias.

Para os três sistemas, considerou-se que o solo se encontrava na capacidade de campo no momento do plantio. Quanto a fonte de água, considerou-se no presente estudo a água como um fator não limitante, tanto no aspecto quantitativo e qualitativo.

Com todas estas informações disponíveis, obteve-se: evapotranspiração de referência total anual (ET0), precipitação total anual (P), capacidade real de armazenamento de água no solo na fase adulta (CRA), evapotranspiração média mensal do cafeeiro na fase adulta (ETca), estimativa da lâmina evapotranspirada anualmente pelo cafeeiro ( $\mathrm{LETC}_{\mathrm{ET}}$ ), estimativa da lâmina bruta anual (LB) e aproveitamento da precipitação na fase adulta (AP).

A evapotranspiração de referência (ET0) diária foi determinada pelo método de PenmanMonteith FAO 56 (ALLEN et al., 1998) (Eq. 1) e a evapotranspiração da cultura (ETc) foi determinada pelo método GESAI (Eq. 2) (MANTOVANI et al., 2012). Na Equação 2, para irrigação por aspersão despreza-se o coeficiente de localização $\left(\mathrm{K}_{\mathrm{L}}\right)$, haja visto que a irrigação é feita em toda área.

$$
\text { ET0 }=\frac{0,408 \Delta\left(R_{n}-G\right)+\gamma \frac{900}{T+273} u_{2}\left(e_{s}-e_{a}\right)}{\Delta+\gamma\left(1+0,34 u_{2}\right)}
$$

Em que, mm dia ${ }^{-1}$;

ET0 - Evapotranspiração de referência,

Rn - Saldo de radiação na superfície da cultura, $\mathrm{MJ} \mathrm{m}^{-2} \mathrm{dia}^{-1}$;

G - Densidade do fluxo de calor do solo, $\mathrm{MJ} \mathrm{m}^{-2} \mathrm{dia}^{-1}$;

$\mathrm{T}$ - Temperatura do ar média diária a $2 \mathrm{~m}$ de altura, ${ }^{\circ} \mathrm{C}$; $\mathrm{m} \mathrm{s}^{-1}$;

$\mathrm{U}_{2}$ - Velocidade do vento a $2 \mathrm{~m}$ de altura,

es - Pressão de vapor de saturação, $\mathrm{kPa}$;

ea - Pressão parcial de vapor, $\mathrm{kPa}$;

$\Delta$ - declividade da curva de pressão de vapor, $\mathrm{kPa}^{\circ} \mathrm{C}^{-1}$, e

$\gamma$ - coeficiente psicrométrico, $\mathrm{kPa}^{\circ} \mathrm{C}^{-1}$.

$$
\mathrm{ETc}=\mathrm{ET} 0 * \mathrm{Kc} * \mathrm{~K}_{\mathrm{L}} * \mathrm{~K}_{\mathrm{S}}
$$

Em que, $\operatorname{dia}^{-1}$;

ETc - Evapotranspiração da cultura, mm

ET0 - Evapotranspiração de referência, mm dia ${ }^{-1}$;

Kc - Coeficiente de cultura, adimensional;

$\mathrm{K}_{\mathrm{L}}$ - Fator de ajuste devido à aplicação localizada da água, adimensional, e

$K_{S}$ - Fator de frequência de irrigação, adimensional.

Utilizou-se para o cálculo do fator de frequência de irrigação ou coeficiente de umidade do solo (Ks) a Equação 3, e para 


\section{DEMANDA HÍDRICA DO CAFEEIRO CONILON IRRIGADO POR DIFERENTES SISTEMAS DE IRRIGAÇÃO}

determinar o fator de ajuste devido à aplicação localizada da água $\left(\mathrm{K}_{\mathrm{L}}\right)$ a metodologia de Keller e Bliesner (1990), conforme Equação 4.

$$
\mathrm{K}_{\mathrm{S}}=\frac{\ln (\mathrm{LAA}+1)}{\ln (\mathrm{CTA}+1)}
$$

Em que,

$\mathrm{K}_{\mathrm{S}}$ - Fator de frequência de irrigação, adimensional;

LAA - Lâmina atual de água no solo, $\mathrm{mm}$, e

CTA - Capacidade total de água no solo, $\mathrm{mm}$.

$$
\mathrm{K}_{\mathrm{L}}=0,1 \sqrt{\mathrm{P}} \quad \text { (Eq. 4) }
$$

Em que,

$\mathrm{K}_{\mathrm{L}}$ - Fator de ajuste devido à aplicação localizada da água, adimensional, e

$\mathrm{P}$ - Percentagem da área sombreada ou molhada (\%) prevalecendo sempre o maior valor.

A capacidade real de armazenamento de água no solo (CRA) foi obtida de acordo com a Equação 5 e a lâmina bruta pela Equação 6.

$\mathrm{CRA}=\left(\frac{\mathrm{CC}-\mathrm{PM}}{10}\right) * \mathrm{Ds} * \mathrm{f} *\left(\frac{\mathrm{PAM}}{100}\right)$

Em que,

CRA - Capacidade real de armazenamento de água no solo, mm

CC - Capacidade de campo, \% peso em base seca;

PM - Ponto de murcha permanente, \% peso em base seca;

Ds - Densidade do solo, $\mathrm{g} \mathrm{cm}^{-3}$;

$\mathrm{f}$ - Fator de disponibilidade de água no solo, adimensional;

Z - Profundidade efetiva do sistema radicular, $\mathrm{cm}$, e

PAM - Percentagem de área molhada, \%.

$$
\mathrm{LB}=\frac{\mathrm{ETc}}{\mathrm{Ei}}
$$

Em que,
LB - Lâmina bruta, mm;

ETc - Evapotranspiração do cafeeiro, mm, e

Ei - Eficiência de irrigação, \%.

Para determinar o aproveitamento da precipitação (AP) por cada sistema, criou-se duas condições simples, sendo elas: $\left(1^{\mathrm{a}}\right)$ se a lâmina média mensal precipitada é menor ou igual a lâmina líquida média mensal, o aproveitamento é de $100 \%$. (2a) se a lâmina média mensal precipitada é maior que a lâmina líquida média mensal, a percentagem de aproveitamento é obtida pela Equação 7.

$$
\mathrm{AP}=\frac{\mathrm{LL}_{\text {mensal }} * 100 \%}{\mathrm{PMM}}
$$

Em que,

AP - Aproveitamento da precipitação, \%,

LLmensal - Lâmina líquida mensal requerida, $\mathrm{mm}$, e

PMM - Precipitação média mensal, mm.

A precipitação média mensal foi a obtida para a fase adulta da cultura, ou seja, com os dados de 2010, 2011, 2012 e 2013. E a LLmensal foi obtida pela Equação 8.

$$
\mathrm{LL}_{\text {mensal }}=\mathrm{NDM} * \mathrm{ETc}
$$

Em que,

LLmensal - Lâmina líquida mensal requerida, $\mathrm{mm}$,

NDM - número de dias do mês em questão, dias; e

ETc - Evapotranspiração média mensal do cafeeiro na fase adulta, mm dia ${ }^{-1}$

\section{RESULTADOS E DISCUSSÕES}

Na Figura 1, estão apresentados os dados de precipitação $(\mathrm{P})$ e de evapotranspiração de referência (ET0) para o município de LinharesES no período de 2007 a 2013. A precipitação média anual para o município é de 1.157,4 mm, segundo o Inmet (2010). Nesse sentido, ao analisar a Figura 1, observa-se que apenas o ano de 2007 não superou a média anual, limitando- 
se a um valor próximo aos $1.000 \mathrm{~mm}$. Em contrapartida no ano de 2009 a precipitação foi bastante elevada, aproximando-se dos 2.000 $\mathrm{mm}$.

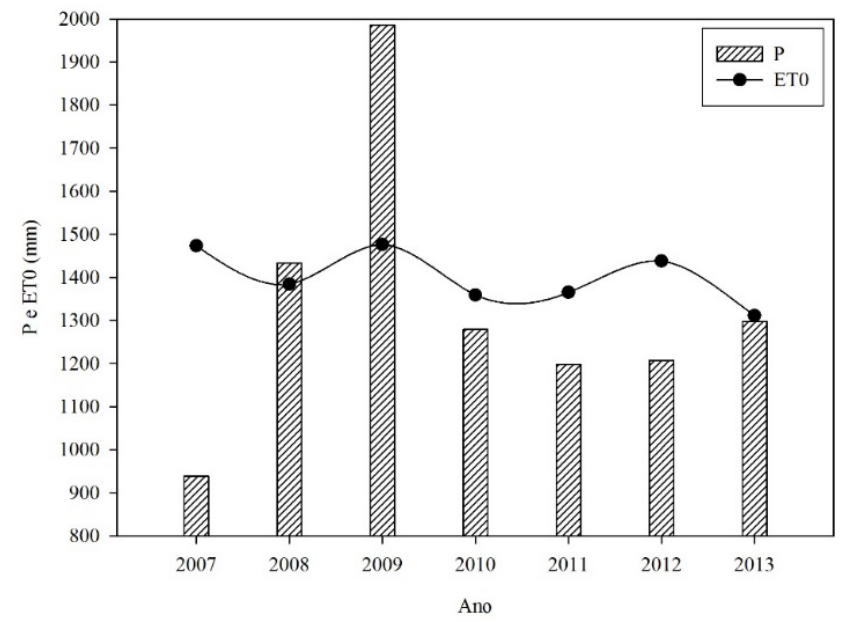

Figura 1. Precipitação total anual (P) e evapotranspiração de referência total anual (ET0) no período de 2007 a 2013, para o município de Linhares-ES.
A precipitação média anual foi superior aos $900 \mathrm{~mm}$ em todos os anos, ultrapassando o limite mínimo exigido pelo cafeeiro durante um ano ou ciclo que é de $800 \mathrm{~mm}$ (BERNARDO et al., 2011). Assim, a partir de uma análise simplória a irrigação poderia ser dispensada. Entretanto, ao considerar a ET0 da região, e a grande variação espacial e temporal das chuvas, que na maioria das vezes não coincidem com as necessidades hídricas da cultura, o uso da irrigação torna-se imprescindível na região, o que explica a grande área irrigada.

A Figura 2 demonstra a importância da irrigação para a cafeicultura no município de Linhares, nela estão apresentados os dados de capacidade real de armazenamento de água no solo (CRA) e da evapotranspiração média mensal do cafeeiro (ETC) na fase adulta da cultura, para os três sistemas estudados.

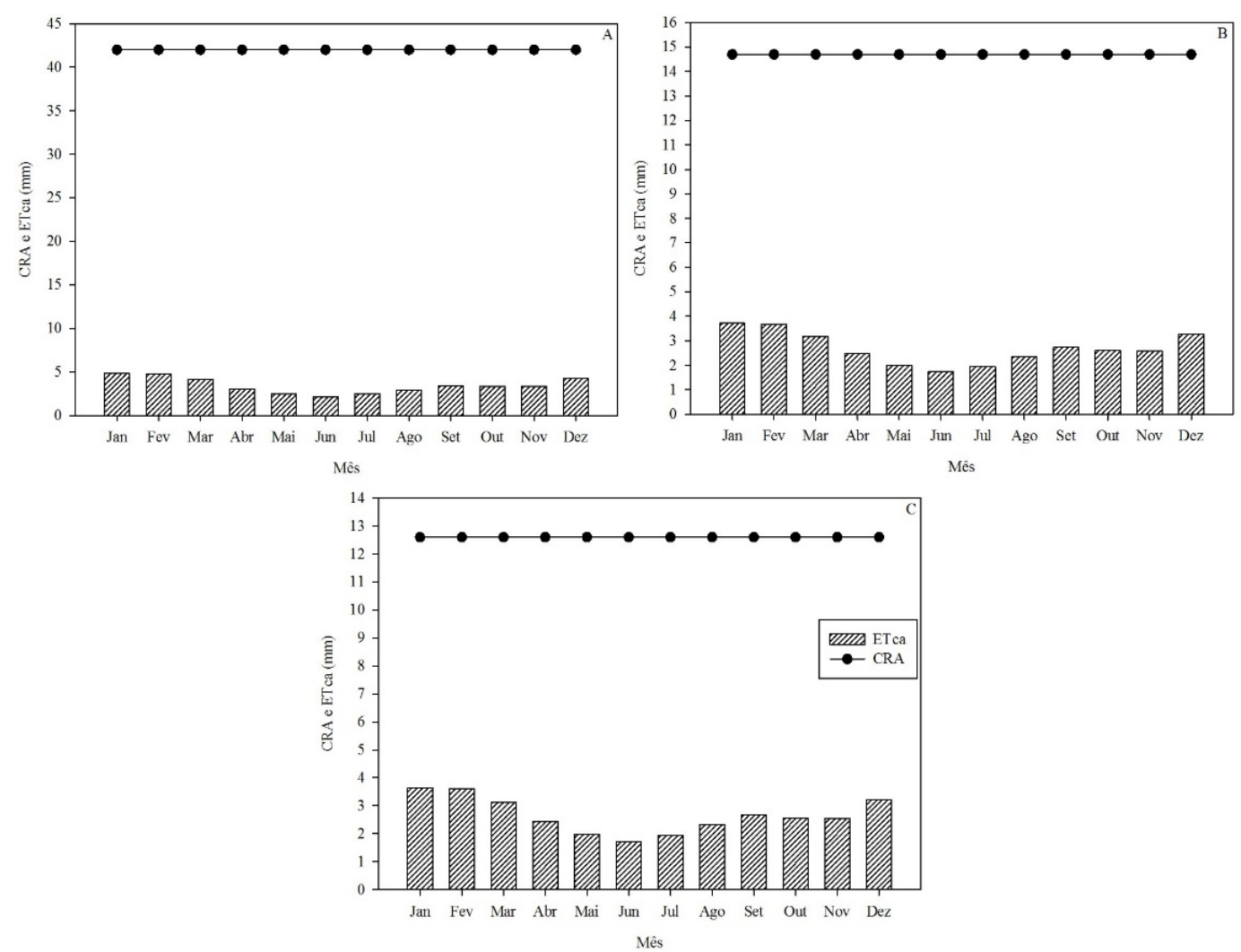

Figura 2. Capacidade real de armazenamento de água no solo na fase adulta (CRA) e evapotranspiração média mensal do cafeeiro na fase adulta (ETca), para o sistema de aspersão setorial (A), microjet (B) e gotejamento (C), no município de Linhares-ES.

Ao analisar a aspersão setorial nos meses de dezembro, janeiro e fevereiro (Figura 2A), com a ETc próxima de $5 \mathrm{~mm} \mathrm{dia}^{-1}$ e a CRA de $42 \mathrm{~mm}$, em 8,4 dias a CRA do solo seria 


\section{DEMANDA HÍDRICA DO CAFEEIRO CONILON IRRIGADO POR DIFERENTES SISTEMAS DE IRRIGAÇÃO}

consumida pela ETc. Esses dados demonstram que neste período com veranicos superiores a 8 dias, há a necessidade de reposição hídrica em cafeeiros adultos. Vale ressaltar que nestes meses, o cafeeiro encontra-se na fase granação dos frutos (PEZZOPANE et al., 2010), período em que a falta de água pode limitar fortemente a produção, aumentando a importância de irrigação na cultura.

Ao analisar as Figuras 2B e 2C, referente aos sistemas de microjet e gotejamento respectivamente, a necessidade de repor água ao solo mais rapidamente, pois a CRA reduz à uma proporção maior que a ETc em função da área molhada por estes sistemas. Dessa forma, poucos dias são necessários para esgotar a CRA do solo. Daí a necessidade de turno de regas pequenos na irrigação localizada, geralmente de 1 a 4 dias (BERNARDO et al., 2011).

Na Figura 3, está apresentado a estimativa da lâmina evapotranspirada anualmente pelo cafeeiro (LETc) entre 2007 e 2013 para a aspersão setorial, gotejamento e microjet.

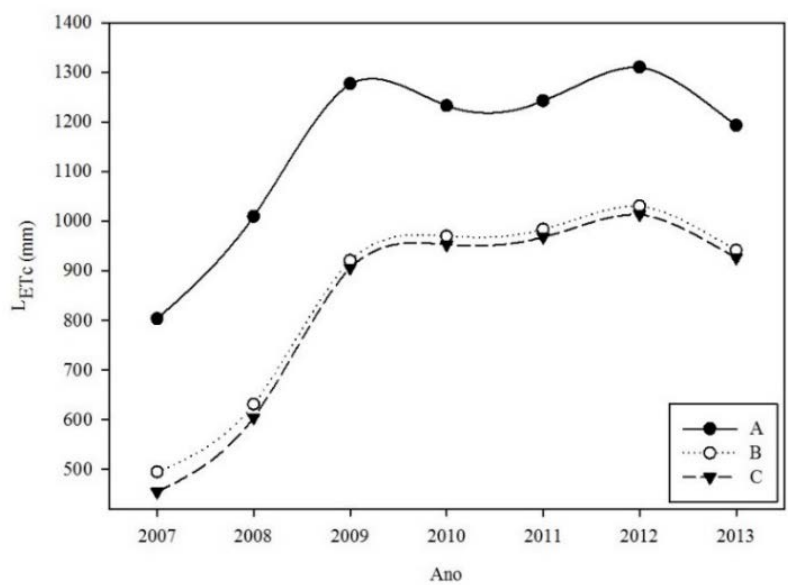

Figura 3. Estimativa da lâmina evapotranspirada anualmente pelo cafeeiro ( $\mathrm{L}_{\mathrm{ETc}}$ ) para o sistema de aspersão setorial (A), microjet (B) e gotejamento (C), no município de Linhares-ES.

Verificou-se, que a maior LETc é obtida quando se realiza a irrigação pelo sistema de aspersão setorial, e menores lâminas nos sistemas de aplicação localizada. Em termos percentuais, a redução da ETc nos sistemas de irrigação por gotejamento e microjet foi de 27,79 e 25,97, respectivamente. Cunha et al. 2014 avaliando a produção de tomate irrigado pelo sistema de gotejamento e por tripa, verificaram menores valores de ETc na irrigação por gotejamento, apesar de considerar a diferença como estreita. A ETc é reduzida, devido a irrigação não ocorrer em área total, como ocorre na aspersão, reduzindo a evaporação direta da água do solo (MANTOVANI et al., 2012).

Ao analisar os dois sistemas com aplicação localizada, verificou-se que a diferença na LETc é pequena, o que pode ser explicado pela grande semelhança entre os sistemas. A diferença mais marcante entre eles está na vazão dos emissores (BERNARDO et al., 2011). Ainda na Figura 3, nota-se o aumento da $L_{E T c}$ do cafeeiro entre o plantio (2007) até atingir a fase adulta (2010), que deve sempre ser levado em conta, tanto para o dimensionamento de projetos quanto para o manejo da irrigação. Entretanto, em muitos casos observa-se uma negligência, principalmente nas propriedades que não possuem um programa de manejo de irrigação implantado.

Na Figura 4, estão apresentados os dados da estimativa da lâmina bruta anual (LB) requerida pelo cafeeiro para os anos de 2007 até 2013 para cada um dos sistemas estudados. $\mathrm{Na}$ aspersão setorial, a somatória da LB aplicada nos sete anos foi 5,85 e 8,76\%, maior em comparação com os sistemas de microjet e gotejamento, respectivamente. Ao comparar os sistemas de irrigação localizada, observou-se que a LB aplicada pelo microjet é apenas 3,09\% superior em relação ao sistema gotejamento.

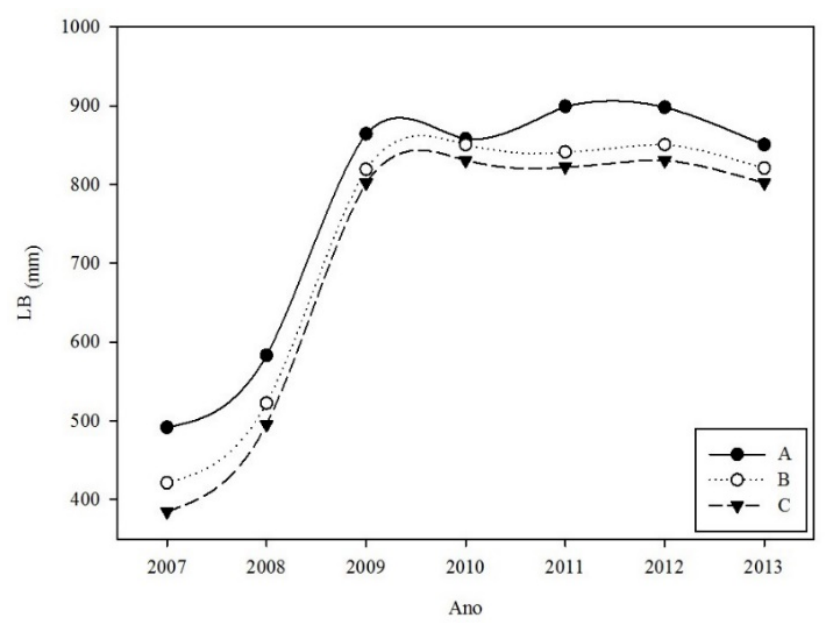

Figura 4. Estimativa da lâmina bruta anual (LB) requerida pelo Conilon para o sistema de aspersão 
setorial (A), microjet (B) e gotejamento (C), no município de Linhares-ES.

Em sistemas de irrigação com aplicação de água localizada, ocorre uma significativa economia de água, uma vez que se irriga apenas a região próxima à planta, além de apresentarem uma maior eficiência de irrigação quando bem manejados. Favorece, ainda, a irrigação localizada o fato de no primeiro ano de cultivo do cafeeiro predominar a evaporação da água do solo sobre a transpiração da cultura (SANTANA et al., 2004), ou seja, a irrigação localizada apresenta baixo potencial de perda da água aplicada no primeiro ano, diferentemente da irrigação por aspersão.

A importância da estimativa do consumo de água pelas culturas é destacada também por Freitas et al. (2008). Para esses autores, o conhecimento da necessidade hídrica máxima diária e total anual de determinada cultura em uma região possibilita dimensionar a rede hidráulica de projetos de irrigação e estimar o volume total de água retirado para suprir suas necessidades hídricas, informação esta, fundamental no gerenciamento de recursos hídricos e no planejamento de projetos hidroagrícolas. É importante ressaltar, que ao optar por sistemas que consomem menos água, também se economiza energia, um dos grandes problemas enfrentados hoje, não só pela agricultura irrigada, mas também pelos diversos setores de produção do Brasil.

No sistema de irrigação por aspersão setorial, o maior consumo de água e energia, pode ser compensando pela possibilidade de realização do plantio de culturas anuais nas suas entrelinhas durante o primeiro e segundo ano, principalmente o milho e o feijão. Já na irrigação localizada essa prática é mais complexa, podendo ser uma barreira para a sua escolha. De acordo Bonomo et al. (2014), além disto, a resistência dos irrigantes por sistemas localizados tem sido relacionada a problemas de entupimento de emissores em razão da qualidade da água dos mananciais da região, em geral, com elevados níveis de ferro e matéria orgânica em suspensão.
A aspersão setorial apresenta um alto aproveitamento das precipitações ao longo de todo ano, com decréscimo no início da época chuvosa (outubro), o que também ocorre para os demais (Figura 5).

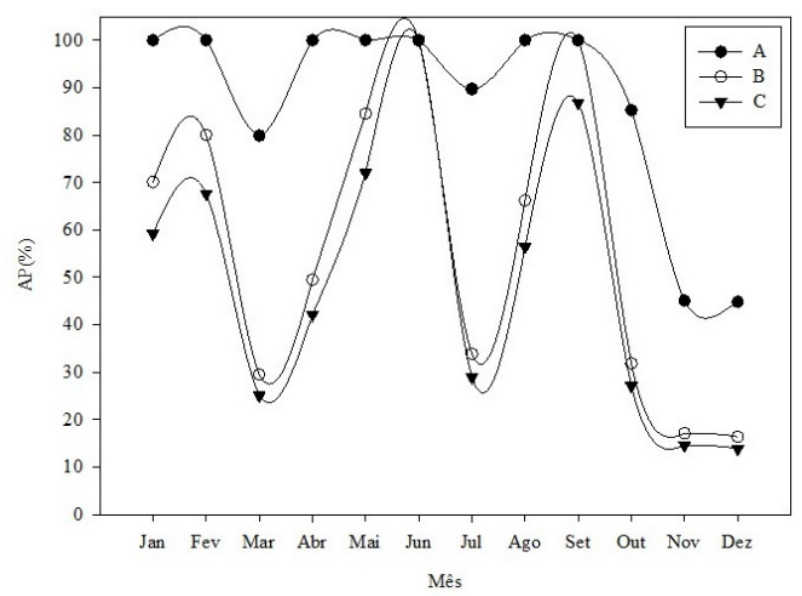

Figura 5. Aproveitamento da precipitação (AP) no cafeeiro Conilon para o sistema de aspersão setorial (A), microjet (B) e gotejamento (C), no município de Linhares-ES.

Devido sua menor capacidade de armazenamento (menor CRA) o cafeeiro irrigado por sistemas de aplicação de água localizada, apresentam na maior parte do ano, um baixo aproveitamento das águas das precipitações, ou seja, a grande maioria das precipitações ocorridas ao longo do ano supera a sua CRA mensal e a água é perdida (percolação ou escoamento). Situação agravada pelo manejo com intervalos curtos entre irrigações, mantendo o solo com um maior conteúdo de água em relação a aspersão.

Dessa forma, no município de LinharesES, considerando a média de precipitação mensal dos anos de 2010, 2011, 2012 e 2013 (fase adulta), a aspersão setorial seria o sistema mais indicado, considerando essa informação como base para escolha de um sistema. Porém deve-se lembrar que os sistemas de aplicação de água localizada, são mais eficientes quanto ao consumo de água e energia.

\section{CONCLUSÕES}

A ETc média foi 27,8 e 26,0\% maior no sistema por aspersão convencional do tipo 


\section{DEMANDA HÍDRICA DO CAFEEIRO CONILON IRRIGADO POR DIFERENTES SISTEMAS DE IRRIGAÇÃO}

setorial em comparação aos sistemas de irrigação por gotejamento e microjet, respectivamente.

A lâmina bruta aplicada nas irrigações foi 5,85 e 8,75\% maior no sistema de irrigação por aspersão setorial em comparação aos sistemas por gotejamento e microjet, respectivamente.

A maior aproveitamento das precipitações ocorre no sistema de irrigação por aspersão.

A tecnologia e os dados gerados são fontes de informação para auxiliar técnicos e engenheiros na escolha do melhor sistema de irrigação e do volume de água requerido por cada um deles.

\section{REFERÊNCIAS}

ALLEN, R. G.; PEREIRA, L. S.; RAES, D.; SMITH, M. Crop evapotranspiration: Guidelines for computing crop water requirements. Rome: FAO, 1998. 300 p. (Irrigation and Drainage Paper, 56).

BERNARDO, S.; SOARES, A. A.; MANTOVANI, E. C. Manual de Irrigação. 8. ed. Viçosa: Editora UFV, 2011. 625p.

BONOMO, D. Z.; BONOMO, R.; PEZZOPANE, J. R. M.; SOUZA, J. M. Alternativas de manejo de água de irrigação em cultivos de Conilon. Coffee Science, v. 9, n. 4, p. 537-545, 2014.

\section{CONAB - Companhia Nacional de}

Abastecimento. Acompanhamento da safra brasileira café, v.2 - Safra 2016, n. 1 - $1^{\circ}$ Levantamento, Brasília: Conab, p. 1-68, 2016. Disponível

em:<http://www.conab.gov.br/OlalaCMS/uploa ds/arquivos/16_01_20_17_01_56_boletim_cafe _-_janeiro_2016.pdf >. Acesso em: 29 jan. 2016.

CUNHA, F. F.; GODOY, A. R. MUCHALAK, S. M.; LIMA, S. F.; LEAL, A. J. F.; BAIO, F. H. R.; GUAZINA, R. A. Produção de cultivares de batata em diferentes sistemas de irrigação. Bioscience Journal, v. 30, n. 1, p. 55-64, 2014.
FERRÃO, R. G.; FONSECA, A. F. A.; FERRÃO, M. A. G.; MUNER, L. H.; VERDIN FILHO, A. C.; VOLPI, P. S.; MARQUES, E. M. G.; ZUCATELI, F. Café Conilon: Técnicas de produção com variedades melhoradas. 3 . ed. Vitória: INCAPER, 2007. 60p. (Circular Técnica).

FREITAS, W. S.; RAMOS, M. M.; COSTA, S. L. Demanda de irrigação da cultura da banana na bacia do Rio São Francisco. Revista Brasileira de Engenharia Agrícola e Ambiental, v. 12, n. 4, p. 343-349, 2008.

INMET - Instituto Nacional de Meteorologia. Normais climatológicas (1961-1999), Versão Revista e Ampliada. Brasília: Inmet, 2010. CDROM.

IRRIPLUS TECNOLOGIA. Softwares educacionais: Software IRRIPLUS ${ }^{\circledR}$ de gerenciamento da irrigação. Disponível em: $<$ http://www.irriplus.com.br/software-irriplus > Acesso em: 10 jul. 2016.

KELLER, J.; BLIESNER, R. D. Sprinkle and trickle irrigation. New York: Van Nostrand Reinold, 1990. 652 p.

MANTOVANI, E. C.; BERNARDO, S.; PALARETTI, L. F. Irrigação: princípios e métodos. 3. eds. Viçosa: Editora UFV, 2012. 355p.

OLIVEIRA, E. L.; FARIA, M. A.; REIS, R. P.; SILVA, M. L. O. Manejo e viabilidade econômica da irrigação por gotejamento na cultura do cafeeiro Acaiá considerando seis safras. Engenharia Agrícola, v. 30, n. 5, p. 887896, 2010.

PEZZOPANE, J. R. M.; CASTRO, F. S.; PEZZOPANE, J. E. M.; BONOMO, R.; SARAIVA, G. S. Zoneamento de risco climático para a cultura do café Conilon no Estado do Espírito Santo. Revista Ciência Agronômica, v. 41, n. 3, p. 341-348, 2010. 
SANTANA, M. S.; OLIVEIRA, C. A. S.; QUADROS, M. Crescimento inicial de duas cultivares de cafeeiro adensado influenciado por níveis de irrigação localizada. Engenharia Agrícola, v. 24, n. 3, p.644-653, 2004.

SANTINATO, R.; FERNANDES, A. L. T.; FERNANDES, D. R. Irrigação na cultura do café. Campinas: Arbore, 1996. 146 p.

TEIXEIRA, M. M.; DAHER, F. A.; BREGONCI, I. S.; REIS, E. F.; RODRIGUES, R. R. Recomendação técnica para implantação e manejo de sistemas de irrigação para a cafeicultura de Conilon no estado do espírito santo. Vitória: Incaper, 2012. 28 p.

TURCO, J. E.; RIZZATI, G. S.; PAVANI, L. C. Influência do manejo da irrigação e sistema de cultivo no rendimento econômico da cultura do feijoeiro irrigado por pivô central. Engenharia na Agricultura, v. 20, n. 2, p. 131-141, 2012.

VIANA, E. G.; BAZONI, A. M. B.; TETZNER, A.; CAPUCHO, M. A.; CELESTRINE, N. M.; DUARTE, D. N.; LOURENÇO, R. S.; PULSCHE, E. T.; SILVA, A. M.; SOUZA, G. A. P.; CARVALHAES JÚNIOR, D.; BARBOSA, D. F. Programa de assistência técnica e extensão rural Proater 2011-2013. Linhares: INCAPER, 2011, 24 p. Disponível em: $<$ http://www.incaper.es.gov.br/proater/municipi os/Nordeste/Linhares.pdf $>$. Acesso em: 10 dez. 2015.

VICENTE, M. R.; MANTOVANI, E. C.; FERNANDES, A. L. T.; DELAZARI, F. T.; FIGUEIREDO, E. M. Efeito de diferentes lâminas de irrigação nas variáveis de desenvolvimento e produção do cafeeiro irrigado por pivô central. Irriga, v. 20, n. 3, p. 528-543, 2015. 